\title{
IMPACT OF CARDIAC REHABILITATION ON PATIENTS WITH HEART FAILURE WITH PRESERVED EJECTION FRACTION
}

\author{
Mahmoud A Hassanein, Sherif W Ayad, Ahmed M El Amrawy and Fady W Eldabe
}

Department of Cardiology, Faculty of Medicine, Alexandria University, Egypt

\section{ABSTRACT}

Background: Heart failure with preserved ejection fraction (HFpEF) represents more than one half of the heart failure (HF) cases worldwide with increased morbidity and mortality. No proven medical treatment till now has shown mortality benefit in HFpEF. This study aims to elucidate the benefit of cardiac rehabilitation (CR) in HFpEF.

Methods: 60 patients with HFpEF included in 2 groups with 1:1 randomization. The first group (the rehabilitation group) received usual medical care plus 2-3 rehabilitation sessions per week for 12 weeks using moderate intensity exercise with $40-75 \%$ of heart rate reserve on treadmill (up to 60 minutes according to the functional capacity). The second group (the control group) received only usual medical care. Comparison between the 2 groups using the percentage of improvement in echocardiographic diastolic function parameters, Minnesota living with heart failure questionnaire (MLWHFQ) and 6 -minute walk test at baseline and after 12 weeks.

Results: we found statistically significant difference between the two groups in favor of the rehabilitation group in the following parameters: a. MLWHFQ (total score mean percentage of reduction) $305.60 \pm 158.44$ versus (vs.) $69.44 \pm 17.71(\mathrm{p}<0.001)$. b. E/e mean percentage of reduction $65.96 \pm 34.55$ vs. $18.23 \pm 13.98(\mathrm{p}<0.001)$. c. Left atrial volume index (LAVI) mean percentage of reduction $27.86 \pm 13.27$ vs. $8.03 \pm 4.40$ $(\mathrm{p}<0.001)$. d. Pulmonary artery systolic pressure mean percentage of reduction was $33.85 \pm 14.68$ vs. $22.97 \pm 16.54(\mathrm{p}=0.02)$. e. 6 -minute walk test $111.79 \pm 40.97$ vs. $46.33 \pm 11.58(\mathrm{p}<0.001)$. f. Body mass index percentage of reduction $10.17 \pm 3.64$ vs. $2.80 \pm 1.60 \mathrm{p}<0.001$. g. Percentage of patients with down-grading of the grade of diastolic dysfunction 10 patients $(33.3 \%)$ vs. 3 patients $(10 \%)(\mathrm{P}=0.028)$. h. No significant difference in left ventricular ejection fraction or other parameters as E/A ratio, left atrial dimension, isovolumetric relaxation time, degree of left ventricular hypertrophy.

Conclusion: Cardiac rehabilitation not only added significant functional improvement in the quality of life and functional capacity but also a significant structural improvement by improving the core items of diastolic function. In the Light of this study, we recommend exercise training based cardiac rehabilitation in $\mathrm{HFpEF}$ management

\section{INTRODUCTION}

The incidence of Heart Failure with preserved ejection fraction (HFpEF) is growing globally. Recent trials showed that approximately $50 \%$ of
Heart failure (HF) hospitalized patients have HFpEF. ${ }^{(1,2)}$ The prevalence of

HFpEF in an Egyptian cohort of hospitalized patients with heart failure was $22 \%{ }^{(3)}$. Women were more likely to present with HFpEF than were men $(29.7 \%$ vs. $10.6 \%, \mathrm{P}$ $<0.001)^{(4)}$.

The main clinical characteristics of HFpEF patients according to data of previous HF surveys are old age, female gender, Hypertension (HTN), diabetes mellitus (DM) and atrial fibrillation (AF) . ${ }^{(5)}$ Although current pharmacological and device therapies showed beneficial effects in heart failure with reduced ejection fraction (HFrEF) patients regarding reduction in mortality, morbidity, hospitalization and improvement of quality of life ,failed to show the same beneficial effects in HFpEF patients especially mortality reduction. ${ }^{(6-8)}$

Exercise training (ET) based cardiac rehabilitation $(\mathrm{CR})$ is documented to have beneficial effects among HFrEF patients in the form of better quality of life and exercise capacity.

.The main impact of CR in heart failure patients is the improvement in the cardio respiratory fitness (CRF) which could be due to reversing cardiac remodeling and amelioration of diastolic function especially in elderly patients. ${ }^{(11,12)}$

The American Heart Association (AHA) and the American College of Cardiology (ACC) consider CR class I indication for HFrEF patients while HFpEF patients are not supported by the current guidelines. ${ }^{(5)}$ The rational beyond this that all the previous large randomized trials excluded $\mathrm{HFpEF}$ patients. Recently few randomized controlled trials including small number of patients showed beneficial impact of CR on HFpEF patients. ${ }^{(12)}$ 
In this study we aimed to evaluate the impact of CR added to the standard medical therapy versus standard medical therapy alone on the functional aspects (quality of life and functional capacity) and the structural aspects (diastolic and systolic function parameters) of HFpEF patients.

\section{METHODS}

\section{- $\quad$ Study Design}

This was a prospective randomized controlled study (1:1 randomization) conducted on $60 \mathrm{HFpEF}$ patients who presented to Alexandria Main University hospital, Alexandria, Egypt. We included patients with established diagnosis HFpEF defined according to the last European society of cardiology (ESC) recommendations (13) We excluded patients with haemodynamically significant valvular disease , acute coronary syndrome as the primary diagnosis, end stage heart failure, severe renal dysfunction (eGFR $<30 \mathrm{ml} / \mathrm{min} / 1.73 \mathrm{~m} 2$ or renal replacement therapy), severe chronic obstructive pulmonary disease (COPD) or asthma ,cognitive decline or major psychiatric pathology, non-ambulatory conditions and orthopedic problems interfering with exercise and life expectancy $<12$ months. Patients were divided into two groups: the rehabilitation group: included thirty $\mathrm{HFpEF}$ patients receiving CR plus pharmacological therapies and the control group: included thirty HFpEF patients receiving pharmacological therapies only.

- Data collection: Regarding demographic data, we registered age, gender, associated comorbidities such as HTN, DM, AF, prior hospitalization with $\mathrm{HF}$ and smoking.

- Functional class assessment: We used the New York Heart Association functional classification (NYHA class) ${ }^{(14,15)}$ to assess the functional class.

- Transthoracic Echocardiography (TTE) :Done at baseline and at the end of ET program with special focus on diastolic function assessment as follows:

a. Mitral A velocity b. Mitral E velocity c. mitral E\A ratio d. Mitral E velocity deceleration time (EDT) e. isovolumetric relaxation time (IVRT) f. pulsed wave tissue Doppler imaging (TDI) derived mitral annular velocities (septal and lateral e') g. estimated LV filling pressures mitral Ele' ratio h. Left atrial volume index (LAVI) i. LA dimension (LAD) j. estimated Pulmonary artery systolic pressure (PASP) by continuous wave (CW) Doppler TR jet velocity $\mathrm{k}$. Diastolic dysfunction (DD) grade (impaired relaxation, pseudo-normal and restrictive filling patterns) ${ }^{(16)}$

- Quality of life (QOL) assessment: Done at baseline and at the end of CR program using the Minnesota living with Heart Failure Questionnaire (MLWHFQ). ${ }^{(17)}$

- Pharmacological therapies :Patients of both groups received optimum medical treatment in the form diuretics, beta blockers, mineralocorticoid antagonists, angiotensin converting enzyme inhibitors (ACEIs) or angiotensin receptor blockers (ARBs) according to the clinical situation and the recommendations of the latest guidelines. ${ }^{(18)}$

- Six-minute walk test $(6 \mathrm{MWT}){ }^{(19,20)}$ : Patients of both groups performed 6MWT at the beginning of the study.

- Symptom limited exercise test : Group I patients only had symptom limited exercise test which was done before CR program for assessment of functional capacity and for utilization of the maximum achieved heart rate during the exercise test in calculating the target heart rate for the CR sessions individually. ${ }^{(2)}$ The test was performed on treadmill using Naughton's protocol (22) which is a submaximal exercise stress protocol used for high risk patients. Clinical assessment of the patients was done before and after the symptom limited exercise test ${ }^{(23)}$. The following data were obtained: resting heart rate, maximum symptom limited heart rate, resting blood pressure, maximum METs achieved.

- Exercise training cardiac rehabilitation program The core rehabilitation program was as follows:

- Mode of exercise: aerobic in nature on a treadmill, consisted of a 12 week program

- Duration of session: 15-60 minutes depending on patient's physical work capacity.

- Frequency of sessions: 2-3 sessions per week.

- Rate of progression was individually tailored according to each patient's physical capacity.

Intensity of exercise corresponding to $40-75 \%$ of heart rate reserve (HRR) based on maximum heart rate that was achieved during symptom limited exercise test. $\mathrm{HRR}=($ maximum HR during exercise test-resting HR) Target $H R=(\text { HRR X }(40-75 \%)+\text { resting HR })^{(24)}$ All sessions were medically supervised via: - The Borg scale for rate of perceived exertion. ${ }^{(25)}$ Telemetry: ECG telemetric monitoring and ambulatory ECG recording to enable the assessment of disturbances of cardiac rhythm or occurrence of myocardial ischemia during session. The telemetry system that was used in the study is manufactured by DMS, model 300-2W wireless system using software Cardiovision 4 that enabled monitoring of up to 4 patients at a time. ${ }^{(24)}$

- Follow up after 12 weeks: At the end of the training program all patients' functional capacity and clinical status were reassessed using: -6MWT -MLWHFQ. -TTE

- Endpoints measurement: The study outcomes were the symptomatic improvement (functional capacity and clinical status) and the improvement in diastolic function by TTE at the end of the CR program.

- Statistical analysis: Data were analyzed using the Statistical Package for Social Sciences (SPSS version 20.0. Armonk, NY: IBM Corp ${ }^{(26)}$.We described qualitative data using number and percent and we 
- described quantitative data using range (minimum and maximum), mean, standard deviation and median. The used tests were Chi-square test for categorical variables to compare between different groups, Fisher's Exact or Monte Carlo correction for chi-square when more than $20 \%$ of the cells have expected count less than 5 ,Mann Whitney test for abnormally distributed quantitative variables, to compare between two studied groups. Values below 0.05are considered significant for all tests.

\section{RESULTS}

Demographic data: The two groups were well matched regarding the baseline characteristics and demographic data. Tables 1 summarize the demographic data and baseline characteristics of the study population
As shown in table $1, \mathrm{CR}$ has a statistically significant impact on the reduction of the body mass index (BMI).

Impact of ET on diastolic function parameters: The comparison between the 2 groups showed statistically significant difference in the $\mathrm{E}$ wave velocity, DD grade, EDT, PASP, septal e', lateral e', E/e` and LAVI denoting more improvement with $\mathrm{CR}$ while no significant difference between the 2 groups was found in the A wave velocity, E/A ratio, EF, LVH degree, LAD and IVRT. Tables 2 and 3 summarize the echocardiographic findings

\section{Quality of Life (MLWHFQ and 6MWT)}

MLWHFQ and 6MWT showed statistically significant more improvement on comparing the 2 groups as shown in table 4 in favor of CR.

Table (1): Comparison between the two studied groups according to demographic data

\begin{tabular}{|c|c|c|c|c|}
\hline Demographic data & $\begin{array}{c}\text { Rehabilitation } \\
\qquad(\mathbf{n}=\mathbf{3 0})\end{array}$ & $\begin{array}{l}\text { Control } \\
(\mathbf{n}=\mathbf{3 0}) \\
\end{array}$ & Test of sig. & $\mathbf{p}$ \\
\hline \multicolumn{5}{|l|}{ Sex } \\
\hline Male & $11(36.7 \%)$ & $13(43.3 \%)$ & \multirow{2}{*}{$\chi^{2}=0.278$} & \multirow{2}{*}{0.598} \\
\hline Female & $19(63.3 \%)$ & $17(56.7 \%)$ & & \\
\hline Age (years) & $57.47 \pm 6.10$ & $58.50 \pm 6.31$ & $\mathrm{t}=0.645$ & 0.521 \\
\hline \multicolumn{5}{|l|}{ BMI $\left(\mathrm{kg} / \mathrm{m}^{2}\right)(\operatorname{mean} \pm \mathrm{SD})$} \\
\hline Baseline & $33.89 \pm 5.17$ & $34.48 \pm 5.35$ & $\mathrm{t}=0.435$ & 0.665 \\
\hline Follow up & $30.77 \pm 4.71$ & $33.51 \pm 5.0$ & $\mathrm{t}=2.186^{*}$ & $0.033^{*}$ \\
\hline$\%$ of reduction & $10.17 \pm 3.64$ & $2.80 \pm 1.60$ & $\mathrm{U}=39.0^{*}$ & $<0.001^{*}$ \\
\hline \multicolumn{5}{|l|}{ Past history } \\
\hline DM & $23(76.7 \%)$ & $20(66.7 \%)$ & $\chi^{2}=0.739$ & \multirow{3}{*}{$\begin{array}{c}0.390 \\
\mathrm{FE}_{\mathrm{p}}=0.492 \\
0.795\end{array}$} \\
\hline HTN & $30(100 \%)$ & $28(93.3 \%)$ & $\chi^{2}=2.069$ & \\
\hline Smoking & $13(43.3 \%)$ & $14(46.7 \%)$ & $\chi^{2}=0.067$ & \\
\hline \multicolumn{5}{|l|}{ Drugs } \\
\hline ACEIs & $13(43.3 \%)$ & $10(33.3 \%)$ & $\chi^{2}=0.635$ & 0.426 \\
\hline ARBS & $4(13.3 \%)$ & $5(16.7 \%)$ & $\chi^{2}=0.131$ & ${ }^{F E} \mathrm{p}=1.000$ \\
\hline Diuretics & $7(23.3 \%)$ & $7(23.3 \%)$ & $\chi^{2}=0.000$ & 1.000 \\
\hline B-blockers / Ca-blockers & $15(50 \%)$ & $8(26.7 \%)$ & $\chi^{2}=3.455$ & 0.063 \\
\hline \multicolumn{5}{|l|}{ Symptoms } \\
\hline Dyspnea & $30(100 \%)$ & $30(100 \%)$ & - & - \\
\hline Chest pain & $8(26.7 \%)$ & $6(20 \%)$ & $\chi^{2}=0.373$ & 0.542 \\
\hline Palpitations & $20(66.7 \%)$ & $16(53.3 \%)$ & $\chi^{2}=1.111$ & 0.292 \\
\hline Syncope & $0(0 \%)$ & $0(0 \%)$ & - & - \\
\hline
\end{tabular}

\section{$\chi^{2}$ : Chi square test, FE: Fisher Exact test, t: Student t-test U: Mann Whitney test}

$\left[\sum \frac{\text { (Baseline value }- \text { Follow up value })}{\text { Baseline value }} X(100)\right] \div \mathrm{n}$ for percentage change calculation

$\mathrm{p}$ : $\mathrm{p}$ value for comparing between the studied groups *: Statistically significant at $\mathrm{p} \leq 0.05$

DM: Diabetes mellitus. HTN: Hypertension. ACEIs: Angiotensin converting enzyme inhibitors. ARBs: Angiotensin receptor blockers. Ca blockers: calcium channel blockers. B blockers: Beta receptors blockers. BMI: Body mass index 
Table (2): Comparison between the two studied groups according to echocardiography parameters (mean value \pm SD)

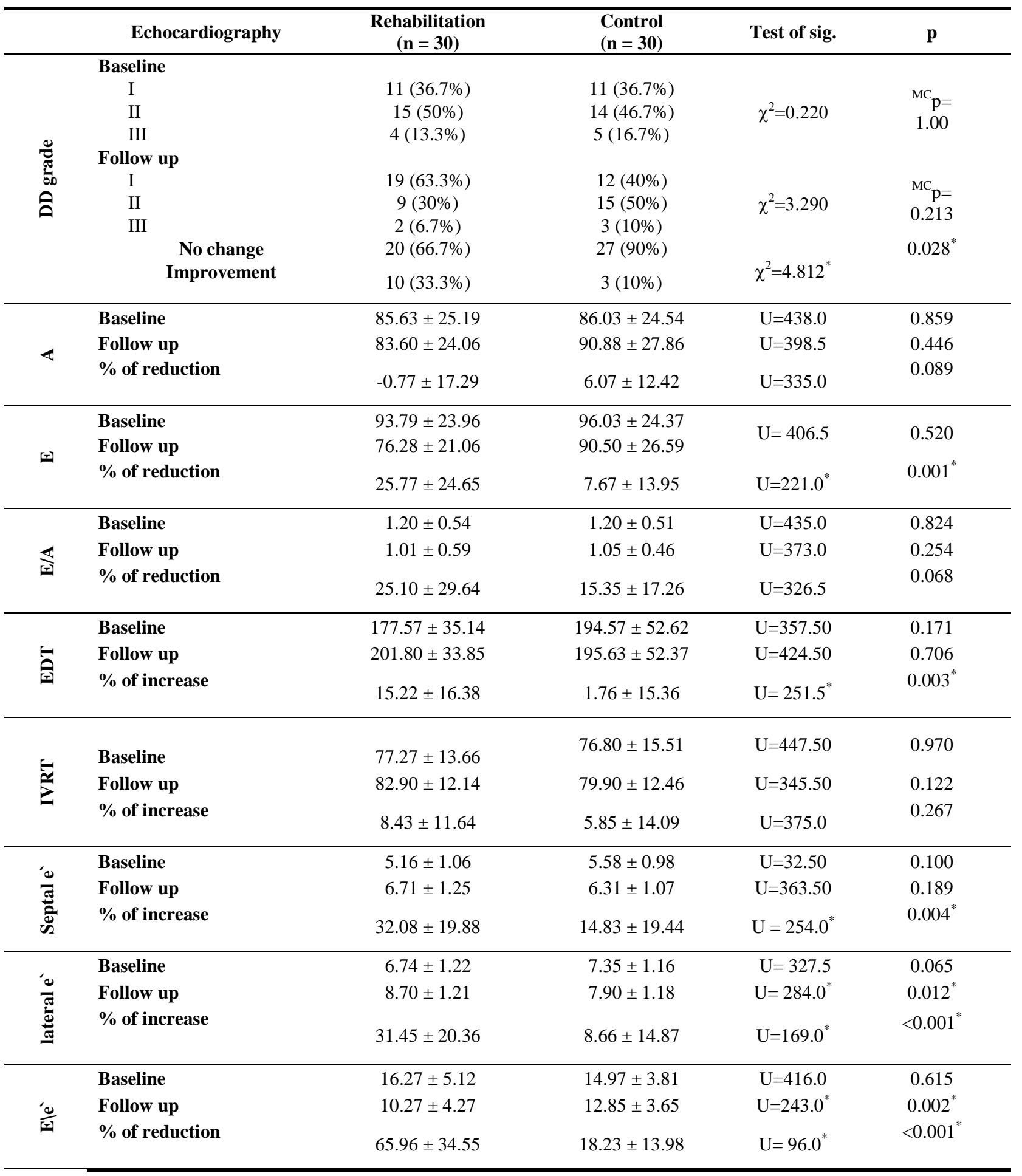

\section{$\chi^{2}$ : Chi square test , MC: Monte Carlo test 'U: Mann Whitney test \\ $\left[\sum \frac{\text { (Baseline value- Follow up value })}{\text { Baseline value }} \mathrm{X}(100)\right] \div \mathrm{n}$ for percentage change calculation}

$\mathrm{p}$ : $\mathrm{p}$ value for comparing between the studied groups $*$ : Statistically significant at $\mathrm{p} \leq 0.05$ DD: Diastolic dysfunction. DT: deceleration time. IVRT: Isovolumetric relaxation time. 
Table (3): Comparison between the two studied groups according to echocardiography data (mean value \pm SD)

\begin{tabular}{|c|c|c|c|c|c|}
\hline & Echocardiography & $\begin{array}{c}\text { Rehabilitation } \\
(\mathbf{n}=\mathbf{3 0})\end{array}$ & $\begin{array}{l}\text { Medical } \\
(n=30)\end{array}$ & Test of sig. & $\mathbf{P}$ \\
\hline \multirow{3}{*}{ 景 } & Baseline & $42.40 \pm 6.54$ & $44.03 \pm 3.07$ & $\mathrm{U}=378.5$ & 0.287 \\
\hline & Follow up & $41.77 \pm 2.39$ & $43.0 \pm 3.11$ & $\mathrm{U}=336.50$ & 0.091 \\
\hline & $\%$ of reduction & $1.60 \pm 15.04$ & $2.47 \pm 3.20$ & $\mathrm{U}=325.0$ & 0.064 \\
\hline \multirow{3}{*}{ 出 } & Baseline & $41.07 \pm 4.18$ & $40.53 \pm 3.87$ & $\mathrm{U}=420.50$ & 0.661 \\
\hline & Follow up & $32.37 \pm 3.99$ & $37.53 \pm 3.45$ & $\mathrm{U}=126.5^{*}$ & $<0.001^{*}$ \\
\hline & $\%$ of reduction & $27.86 \pm 13.27$ & $8.03 \pm 4.40$ & $\mathrm{U}=55.0^{*}$ & $<0.001^{*}$ \\
\hline \multirow{3}{*}{ 离 } & Baseline & $43.27 \pm 8.99$ & $41.70 \pm 8.92$ & $\mathrm{U}=393.0$ & 0.395 \\
\hline & Follow up & $32.50 \pm 6.76$ & $34.10 \pm 7.13$ & $\mathrm{U}=406.0$ & 0.505 \\
\hline & $\%$ of increase & $33.85 \pm 14.68$ & $22.97 \pm 16.54$ & $\mathrm{U}=242.5^{*}$ & $0.02^{*}$ \\
\hline \multirow{3}{*}{ 岌 } & Baseline & $66.93 \pm 6.59$ & $66.90 \pm 7.40$ & $\mathrm{U}=432.0$ & 0.789 \\
\hline & Follow up & $67.43 \pm 5.61$ & $67.20 \pm 7.67$ & $\mathrm{U}=433.50$ & 0.807 \\
\hline & $\%$ of increase & $1.05 \pm 5.84$ & $0.84 \pm 9.27$ & $\mathrm{U}=447.5$ & 0.970 \\
\hline \multirow{3}{*}{ 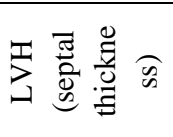 } & Baseline & $11.43 \pm 1.76$ & $11.43 \pm 1.70$ & $\mathrm{U}=443.5$ & 0.922 \\
\hline & Follow up & $10.80 \pm 1.75$ & $11.17 \pm 1.53$ & $\mathrm{U}=395.0$ & 0.402 \\
\hline & $\%$ of decrease & $6.22 \pm 7.30$ & $2.37 \pm 6.17$ & $\mathrm{U}=337.5$ & 0.065 \\
\hline
\end{tabular}

U: Mann Whitney test $\quad \mathrm{p}$ : $\mathrm{p}$ value for comparing between the studied groups $\left[\sum \frac{\text { (Baseline value- Follow up value) }}{\text { Baseline value }} X(100)\right] \div \mathrm{n}$ for percentage change calculation

*: Statistically significant at $\mathrm{p} \leq 0.05$

LAD: Left atrial dimension. LAVI; left atrial volume index. PASP: Pulmonary artery systolic pressures. EF: Ejection fraction. LVH: Left ventricular hypertrophy

Table (4): Comparison between the two studied groups according to Total score of MLWHFQ and 6MWT (mean value \pm SD)

\begin{tabular}{llcccc}
\hline & $\begin{array}{c}\text { Rehabilitation } \\
(\mathbf{n = 3 0})\end{array}$ & $\begin{array}{c}\text { Control } \\
(\mathbf{n = 3 0})\end{array}$ & Test of sig. & p \\
\hline & Baseline & $66.23 \pm 11.13$ & $62.23 \pm 14.06$ & $\mathrm{U}=335.5$ & 0.090 \\
& $\begin{array}{l}\text { Follow up } \\
\text { \% of reduction }\end{array}$ & $19.60 \pm 11.95$ & $37.23 \pm 10.19$ & $\mathrm{U}=80.0^{*}$ & $<0.001^{*}$ \\
& & $305.60 \pm 158.44$ & $69.44 \pm 17.71$ & $\mathrm{U}=64.0^{*}$ & $<0.001^{*}$ \\
\hline & Baseline & $225.33 \pm 52.11$ & $246.33 \pm 45.45$ & $\mathrm{U}=338.50$ & 0.098 \\
& Follow up & $466.67 \pm 95.96$ & $358.0 \pm 58.92$ & $\mathrm{U}=154.5^{*}$ & $<0.001^{*}$ \\
\hline
\end{tabular}

U: Mann Whitney test $\mathrm{p}$ : $\mathrm{p}$ value for comparing between the studied groups, *: Statistically significant at $\mathrm{p} \leq 0.05$

$\left[\sum \frac{\text { (Baseline value- Follow up value) }}{\text { Baseline value }} \times(100) \div 1\right.$ for percentage change calculation

MLWHFQ: Minnesota living with heart failure questionnaire. 6MWT: 6-minute walk test

\section{DISCUSSION}

This study was designed to evaluate the impact of exercise based CR in HFpEF regarding the quality of life and a more detailed assessment of this impact on the LV diastolic and systolic function. Few trials in the literature have studied this impact on HFpEF patients. On reviewing the literature, few relevant trials have studied the impact of exercise-based CR on HFpEF patients using different protocols of exercise and different inclusion and exclusion criteria finally coming with variable results of the impact of CR on the improvement of LV diastolic function and QOL in HFpEF patients. ${ }^{(27)}$
On reviewing the previous trials that have studied the impact of ET on HFpEF, we found large variation in the designs of those studies regarding different aspects. The duration of the ET protocol varied from 12 to 16 weeks in most studies ${ }^{(27)}$ although some studies used shorter protocols as the 4-week ET program in the study done by Angadi et al $^{(28)}$ and other longer protocols such as the 20week protocol which was reported by Kitzman et al 2016. ${ }^{(29)} \quad$ Also the ET was done in variable settings whether home based outpatient setting or a supervised program done in rehabilitation centers. The mode of ET 
also varied where some studies used a combination of endurance and resistance training, others adopted walking on a treadmill and other studies used the bicycle ergometer. ${ }^{(27)}$

In our study, we followed a 12-week ET program using walking on a treadmill as the core of our CR program. We do believe that this design was appropriate for keeping the compliance of the patients with no patients lost in the follow up in our study. This design with moderate intensity ET also was comfortable for the patients and helped our patients to complete all their rehabilitation sessions successfully. The patients in the control group were followed clinically on regular basis and they had open easy access to the cardiology clinic for any inquiries.

\section{Improvement of the echocardiography parameters:}

1. Our finding of an improvement in the DD grade was not studied in any of the previous trials discussing the impact of CR on HFpEF ${ }^{(27)}$ except Angadi et al ${ }^{(28)}$ who reported significant change in the DD grade $(2.1 \pm 0.3$ pre ET vs $1.3 \pm 0.7$ post ET, $\mathrm{p}<0.01$ ) only with high intensity interval training not in the moderate intensity ET as the one used in our study. However, this difference can be explained by the only 15 patients included and the shorter duration (4 weeks) in the study of Angadi et al.

2.E/A ratio, DT and IVRT: in our study, these finding are consistent with the findings reported by Angadi et al ${ }^{(28)}$, Kitzman et al $2010^{(30)}$, Kitzman et al $2013^{(31)}$ and Smart et al ${ }^{(32)}$. Alves et al ${ }^{(33)}$ reported that ET increased the mean E/A ratio and decreased DT of early filling in patients with mild and preserved EF. However ,mitral inflow velocities and the LV filling patterns are important parameters as they are linked to the functional class and prognosis in $\mathrm{HF}$ in general although the change in early mitral $\mathrm{E}$ wave velocity should be used cautiously because it is dependent on variable parameters as myocardial relaxation and the preload state of the patient ${ }^{(34)}$

3. Septal e', lateral $\mathrm{e}^{\prime}$ and E/e': Many of the previous trials didn't include the estimation of the LV filling pressures using the E/e in its results for assessing the diastolic function improvement ${ }^{(27)}$. Edelmann et al ${ }^{(35)}$ reported statistically significant improvement in the E/e' with CR in HFpEF. In contrary to our study, Edelmann et al ${ }^{(35)}$ did not include patients with grade III diastolic dysfunction and used a combination of resistance and endurance ET in the CR program. We also found a consistent finding in our study where CR resulted in a significant reduction in the $\mathrm{E} / \mathrm{e}^{\prime}$ ratio denoting an important structural basis for the benefit of $\mathrm{CR}$ in HFpEF. Other trials as Smart el al ${ }^{(32)}$, Angadi et $a l^{(28)}$ and Kitzman $2016^{(29)}$ didn't report statistically significant difference in the LV filling pressures with ET .An additional point in our study is the statistically significant increase in the septal and lateral $\mathrm{e}^{\prime}$ with CR. This represents another point in the structural basis of the CR benefit in HFpEF.
4.LAD and LAVI: None of the previous trials reported a change in the LAD with $\mathrm{CR}^{(27)}$ and our finding are consistent with this. We investigated a more accurate measure of LA dilatation which is the LAVI that is more representative of the LA enlargement. Edelmann et al ${ }^{(35)}$ reported a statistically significant reduction in the LAVI (LAVI decreased with ET and remained unchanged with usual care $(-4.0,95 \% \mathrm{CI}:-5.9$ to -2.2 , $\mathrm{p}<0.001)$. our study came with a consistent finding. Angadi et al $^{(28)}$ did not find a statistically significant difference in the LA volume index with ET. We do believe that the significant improvement in the LA volume index, septal e', lateral e' and E/e` represents a core of structural basis for the significant additive benefit of CR.

5.PASP: None of the previous trials reported significant change in the PASP with $\mathrm{CR}^{(27)}$. In our study we found a significant reduction in the PASP with CR adding a more benefit in the structural basis of the CR benefit in HFpEF.

6.LVH: LVH was not reported in most trials. Some trials reported LV mass with no change with $\mathrm{CR}$ such as Edelmann et al ${ }^{(35)}$ and Kitzman et al $2016^{(29)}$. In our study we did not find a change in the LVH with CR.

7.EF: None of the trials reported a significant change or improvement in the EF with $\mathrm{CR}^{(27)}$ except Alves et al (33) who found significant improvement in the EF in HFpEF putting in consideration that this was achieved after prolonged 6-month ET program. We also did not find any significant difference in the EF with CR.

QOL improvement: In our study we found a significant improvement in the quality of life using the MLWHFQ .Other previous trials stated an improvement in the quality of life although they used different modalities or questionnaires such as Gary et al ${ }^{(36)}$ and Alves et al ${ }^{(33)}$. $\mathrm{Fu}$ et $a l^{(37)}$ used the MLWHFQ and found a reduction in it with CR. Other trials assessed the peak oxygen uptake and found a significant improvement as Kitzman et al $2013^{(31)}$ and Smart et al ${ }^{(32)}$

Most of the items of the MLWHFQ showed significant improvement in both the physical and psychosocial aspects with CR in our study.

6 MWT: In our study, we found a significant improvement in the 6MWT with CR. This result is consistent with what was stated by Gary et al (36) and Kitzman et al $2010^{(30)}$. On the other hand, Maldonado et al ${ }^{(38)}$ and Edelmann et al (35) reported no significant difference in the 6MWT with CR although it was higher than the baseline values in both groups of the study but the different study design and inclusion of large number of patients with mild LV diastolic dysfunction especially by Edelmann et al ${ }^{(35)}$ may have caused this difference population.

Study limitations: Our study is single center study despite we included reasonable number of patients. We did not include prolonged follow up of the patients to assess the long term impact of ET and whether the 
beneficial effect shown with ET will be maintained for long term or not. Also the echocardiographic measurements were done at rest and no measurements were done with exercise which may have shown further additive data. We excluded patients with severe comorbidities which may interfere with ET which may have an impact on the results where comorbidities with various severity occur commonly in HFpEF.

\section{CONCLUSIONS}

In the light of our study, we have shown that CR based on a 12-week aerobic moderate intensity endurance ET program is beneficial, safe, and feasible with high patient compliance. CR can add significant positive impact on both the functional aspects with significant improvement in the QOL and the structural aspects with significant improvement of the diastolic function parameters. Our final recommendation is the addition of ET based CR as an essential part of the management strategy of HFpEF. The long term morbidity and mortality benefits of CR in HFpEF still need to be studied in further trials.

\section{REFERENCES}

1. Owan TE, Hodge DO, Herges RM, Jacobsen SJ, Roger VL, Redfield MM. Trends in prevalence and outcome of heart failure with preserved ejection fraction.NEngl J Med. 2006; 355:251-9.

2. Bhatia RS, Tu JV, Lee DS, Austin PC, Fang J, Haouzi A, et al. Outcome of heart failure with preserved ejection fraction in a population-based study.NEngl J Med. 2006; 355:260-269.

3. Hassanein M, Abdelhamid M, Ibrahim B, Elshazly A, Aboleineen MW, Sobhy H, et al. Clinical characteristics and management of hospitalized and ambulatory patients with heart failure results from ESC Heart Failure LongTerm Registry Egyptian cohort. ESC Heart Failure 2015; 2: 159-67.

4. Hassanein M, Abdelhamid M, Ibrahim B, Sobhy M, Nasr $\mathrm{G}$, Aboleineen $\mathrm{M}$, et al. Gender differences in Egyptian hospitalized with heart failure: insights from the European Society of Cardiology Heart Failure Long-Term Registry. ESC Heart Fail. 2018 Dec; 5(6): 1159-64.

5. Yancy CW, Jessup M, Bozkurt B, Butler J, Casey DE, Colvin MM, et al. 2017 ACC/AHA/HFSA Focused Update of the 2013 ACCF/AHA Guideline for the Management of Heart Failure: A Report of the American College of Cardiology/American Heart Association Task Force on Clinical Practice Guidelines and the Heart Failure Society of America. J Card Fail. 2017;23:628-51.

6. Massie BM, Carson PE, McMurray JJ, Komajda M, McKelvie R, Zile MR, et al. Irbesartan in patients with heart failure and preserved ejection fraction.NEngl $\mathrm{J}$ Med. 2008; 359:2456-67.

7. Yusuf S, Pfeffer MA, Swedberg K, Granger CB, Held P, McMurray JJ, et al. Effects of candesartan in patients with chronic heart failure and preserved left-ventricular ejection fraction: the CHARM-Preserved Trial.Lancet. $2003 ; 362: 777-81$.

8. Bergström A, Andersson B, Edner M, Nylander E, Persson H, Dahlström U. Effect of carvedilol on diastolic function in patients with diastolic heart failure and preserved systolic function. Results of the Swedish
Doppler-echocardiographic study (SWEDIC).Eur J I Fail. 2004; 6:453-61

9. O'Connor CM, Whellan DJ, Lee KL, Keteyian SJ, Cooper LS, Ellis SJ, et al. Efficacy and safety of exercise training in patients with chronic heart failure: HFACTION randomized controlled trial.JAMA. 2009; 301:1439-50.

10. Haykowsky MJ, Liang Y, Pechter D, Jones LW, McAlister FA, Clark AM. A meta-analysis of the effect of exercise training on left ventricular remodeling in heart failure patients: the benefit depends on the type of training performed.J Am CollCardiol. 2007; 49:2329-36.

11. Braverman DL. Cardiac rehabilitation: a contemporary review. Am J Phys Med. 2011;90: 599-611.

12. 2020 ESC Guidelines on sports cardiology and exercise in patients with cardiovascular disease. European Heart Journal (2020) 00, 1_80.

13. How to diagnose heart failure with preserved ejection fraction: the HFA-PEFF diagnostic algorithm: a consensus recommendation from the Heart Failure Association (HFA) of the European Society of Cardiology (ESC) European Heart Journal (2019) 40, 3297-317

14. Dolgin M. Nomenclature and criteria for diagnosis of diseases of the heart and great vessels / the Criteria Committee of the New York Heart Association. $9^{\text {th }}$ ed. Boston : Little, Brown; 1994.

15. van den Broek SA, van Veldhuisen DJ, de Graeff PA, Landsman ML, Hillege H, Lie KI. Comparison between New York Heart Association classification and peak oxygen consumption in the assessment of functional status and prognosis in patients with mild to moderate chronic congestive heart failure secondary to either ischemic or idiopathic dilated cardiomyopathy. Am J Cardiol 1992; 70 (3):359-63.

16. SherifF.Nagueh, Otto.A.Smeiseth, Christopher P.Appleton, et al. Recommendations for evaluation of left ventricular diastolic functionby echocardiography. An update from the American society of echocardiography and the European association of cardiovascular medicine.J Am SocEcchocardiography 2016;29: 277-3014

17. Garin O, Herdman M, Vilagut G, Ferrer M, Ribera A, Rajmil L, et al. Assessing health-related quality of life in patients with heart failure: a systematic, standardized comparison of available measures. Heart Fail Rev 2014; 19 (3): 359-67.

18. PiotrPonikowski, Adriaan A Voors, Stefan D Anker. The Task Force for the diagnosis and treatment of acute and chronic heart failure of the European Society of Cardiology. European Heart Journal.2016: 37: 2157.

19. Roberts E, Li FK, Sykes K. Validity of the 6-minute walk test for assessing heart rate recovery after an exercise-based cardiac rehabilitation programme. Physiotherapy 2006; 92 (2):116-21.

20. ATS Committee on Proficiency Standards for Clinical Pulmonary Function Laboratories. ATS statement: guidelines for the six-minute walk test. Am J RespirCrit Care Med 2002; 166 (1) :111-7.

21. Arena R, Myers J, Williams MA, Gulati M, Kligfield P, Balady GJ, et al. Assessment of functional capacity in clinical and research settings: a scientific statement from the American Heart Association Committee on Exercise, Rehabilitation, and Prevention of the Council on Clinical Cardiology and the Council on Cardiovascular Nursing. Circulation 2007; 116 (3):329-43.

22. Naughton JP, Hellerstein HK. Exercise testing and exercise training in coronary heart disease. New York: Academic Press, Inc; 1973. 
23. Garner KK, Pomeroy W, Arnold JJ. Exercise Stress Testing: Indications and Common Questions. Am Fam Physician 2017; 96 (5) 293-9.

24. Kouidi E, Farmakiotis A, Kouidis N, Deligiannis A. Transtelephonic electrocardiographic monitoring of an outpatient cardiac rehabilitation programme. ClinRehabil 2006; 20 (12):1100-4.

25. Purvis JW, Cureton KJ. Ratings of perceived exertion at the anaerobic threshold. Ergonomics 1981; 24(4)295 300.

26. Kirkpatrick LA, Feeney BC. A simple guide to IBM SPSS statistics for version 20.0. Student ed. Belmont, Calif.: Wadsworth, Cengage Learning; 2013.

27. Massimo Leggio1, Augusto Fusco , Claudia Loreti , Giorgio Limongelli1, Maria GraziaBendini, Andrea Mazza, et al. Effects of exercise training in heart failure with preserved ejection fraction: an updated systematic literature review Heart Failure Reviews (2020) 25:703$711 \mathrm{https}: / /$ doi.org/10.1007/s10741-019-09841-X

28. Angadi SS, Mookadam F, Lee CD, Tucker WJ, Haykowsky MJ, Gaesser GA (2015) High-intensity interval training vs. moderateintensity continuous exercise training in heart failure with preserved ejection fraction: a pilot study. J ApplPhysiol 119(6):753-8 . https://doi.org/10.1152/japplphysiol.00518.2014

29. Kitzman DW, Brubaker PH,Morgan TM, Haykowsky M, Hundley G, Kraus WE, et al (2016) Effect of caloric restriction or aerobic exercise training on peak oxygen consumption and quality of life in obese older patients with heart failure with preserved ejection fraction: a randomized clinical trial. JAMA 315(1):36-46. https://doi.org/10.1001/jama.2015.17346

30. Kitzman DW, Brubaker PH, Morgan TM, Stewart KP, Little WC(2010) Exercise training in older patients with heart failure andpreserved ejection fraction: a randomized, controlled, single-blindtrial. Circ Heart Fail 3(6):659-67. https://doi.org/10.1161/CIRCHEARTFAILURE.110.958785

31. Kitzman DW, Brubaker PH, Herrington DM, Morgan TM, Stewart KP, Hundley WG, et al. (2013) Effect of endurance exercise training on endothelial function and arterial stiffness in older patients with heart failure and preserved ejection fraction: a randomized, controlled, single-blind trial. J Am CollCardiol 62(7):584-92. https://doi.org/10.1016/j.jacc.2013.04.033

32. Smart NA, Haluska B, Jeffriess L, Leung D (2012) Exercise training in heart failure with preserved systolic function: a randomizedcontrolled trial of the effects on cardiac function and functionalcapacity. Congest Heart Fail 18(6):295-301. https://doi.org/10.1111/j.1751-7133. 2012.00295.x

33. Alves AJ, Ribeiro F, Goldhammer E, Rivlin Y, Rosenschein $\mathrm{U}$, Viana JL,et al. Exercise training improves diastolic function in heart failure patients. Med Sci Sports Exerc. 2012; 44:776-85.

34. Giannuzzi P, Temporelli PL, Bosimini E, et al. Independent and incremental prognostic value of Doppler-derived mitral deceleration time of early filling in both symptomatic and asymptomatic patients with left ventricular dysfunction. J Am Coll Cardiol. 1996; 28 (2): 383-90.

35. Edelmann F, Gelbrich G, Düngen HD, Fröhling S, Wachter R,Stahrenberg R, et al.(2011) Exercise training improves exercise capacity and diastolic function in patients with heart failure with preserved ejection fraction: results of the Ex-DHF (exercise training in diastolic heart failure) pilot study. J Am CollCardiol 58(17):1780-91.

https:// doi.org/10.1016/j.jacc.2011.06.054

36. Gary RA, Sueta CA, Dougherty M, Rosenberg B, Cheek $\mathrm{D}$, Preisser $\mathrm{J}$, et al. Home-based exercise improves functional performance and quality of life in women with diastolic heart failure. Heart Lung. 2004;33:210-18.

37. Fu TC, Yang NI, Wang $\mathrm{CH}$, et al. Aerobic interval training elicits different hemodynamic adaptations between heart failure patients with preserved and reduced ejection fraction. Am J PhysMedRehabil 2016;95: 15-27. Crossref | PubMed

38. Maldonado-Martín S, Brubaker PH, Eggebeen J, Stewart KP, Kitzman DW (2017) Association between 6-minute walk test distanceand objective variables of functional capacity after exercisetraining in elderly heart failure patients with preserved ejectionfraction: a randomized exercise trial. Arch Phys Med Rehabil98 (3):6003.https://doi.org/10.1016/j.apmr.2016.08.481 